\title{
Effects of COVID-19 and Recommended Practices: Case Report
}

\author{
R. Jegan \\ Assistant Professor, Department of Biomedical Engineering, \\ Karunya Institute of Technology and Sciences, Coimbatore-641114, India
}

\begin{abstract}
Objectives: Over the past one year, the effect of 2019-nCoV is drastically increasing and affecting entire human population. Due to these pandemic situations, people are facing many health-related problems which includes life threatening fears, heart problems, taking more unneeded medicine and most importantly critical thinking which leads to mental stress. This paper proposes the different possible strategies which help the people for avoiding these issues.

Case Presentation: An approach for delivering a possible strategy on avoiding human health issues due to COVID-19 is done by the successful collection of reports from many infected people. The information from physical examination to successful treatment stages were analyzed from different infected patients and reported. Here, we reviewed the methodologies adopted for preventing the spread of corona virus from various origin and have listed the characteristic features of its behavior based on the real case reports.

Method: The different age group patients are reviewed and possible relevant characteristic points on the important protocol, treatment procedure, steps to control the spread of this virus, guidelines to avoid other health issues and maintaining body health for fighting COVID-19 were collected and presented in the form of case reports.

Conclusion: The different techniques which are presented in this paper help the patients as well as people in the world to face the pandemic situation very effectively mainly to live with COVID-19. This paper also presents the prospective study and summarizes the effects of corona virus in human health based on the infected patients experience. The systematic review on the characteristics of corona virus will provide a strong guideline to the people to identify and face the critical situation in very informative manner.
\end{abstract}

Keywords: 2019-nCoV, COVID-19, Mental Stress, Treatment, Medicine.

\section{Introduction}

Over the last few months, many patients are suffering and severely affected due to novel corona virus. The nature of this virus is that it spreading from one origin to another origin mainly passed through infected respiratory droplets and people having repeated contact with infected person. The report says that, corona virus on human body from infection to symptom identification can be upto 14 days (incubation period). In healthcare networks, there are many diseases which have been treated well by our doctors and medical personnel's in very effective ways. These diseases are spreading and affects the human environments based on its unique nature. As of now, the effect induced by this coronavirus may vary from mild symptoms to severe symptoms. The severe effect of this virus affects the patient's respiration system. The first corona virus in human $(\mathrm{CoV})$ were observed in the year 1965 and causing many problems to the human such as respiratory problems, issues on gastrointestinal, and neurological infections. The different families of $\mathrm{CoV}$ were listed in the papers are generally affecting human's respiration and associated with common cold issue ${ }^{1,2}$. But in the year 2003, it was identified that the coronavirus causes the severe acute respiratory syndrome among the humans and notified, it may create an epidemic disease to the world. The report says that, in the year 2012, new coronavirus affected 
many people which is considered to be a global threat ${ }^{3}$. Recently, in the month of December 2019, patient with respiratory problem have been admitted and reported in Wuhan, Hubei province, China. The patient was tested and found their clinical identification with respect to disease looks like normal pneumonia. Due to severe respiratory issue, later it was identified as severe acute respiratory syndrome coronavirus ${ }^{4}$. It was identified by the Chinese Center for Disease Control and Prevention (CDC) by patient clinical data from the throat swab sample. The World Health Organization (WHO) has given the name of this virus as $2019-\mathrm{nCoV}$ and declared the public health emergency due to spreading of corona virus in the month of January 2020. The effect of coronavirus disease mainly creating the problem of pneumonia which are very similar to SARS and MERS. Currently, the main symptoms presented by patients with 2019-nCoV are fever, cough, myalgia, fatigue, expectoration, headache, and gastrointestinal symptoms such as diarrhea ${ }^{4}$. This new $2019-\mathrm{nCoV}$ belongs to beta-CoV type and to the subgenus Sarbecovirus ${ }^{5}$. The International Committee on Taxonomy of Viruses (ICTV) has given the name of this virus as SARS-CoV2 and the induced disease as COVID- $19^{6}$.

In the present situation, due to lack of medicine, the important identical procedure to stop this virus spreading is to follow the safety measures such as wearing a medical mask, proper rest and ventilation, avoiding unnecessary travels in the crowd, drink more water and take healthy foods. The most important way to control the spread of this virus is to stay home. But, the long term staying at home creates many health problems. The people are facing different kinds of health issues during the period of COVID-19 pandemic situations. Due to the threat of this virus nature, people are forced to think differently when they are staying at home. This leads to mental stress and heart problems among the populations. Therefore, there is necessary to report the effect of coronavirus and provide an essential guideline to the society to fight this virus. This paper provides the necessary information's on various approaches and method applicable for fighting COVID-19 through different case reports. The analysis of these case reports will help the society to recognize and manage the situation very effectively. The reminder of this paper is organized as follows: section 2 presents a brief information's extracted from COVID-19 infected patients. Section 3 presents the detailed discussion and caution steps towards fighting COVID-19.

Case Reports: COVID-19 is the life-threatening disease which is spreading all over the world. The symptoms of the disease vary from human to human and also the effects of COVID-19 differ for each person. The severity of the disease depends on the age and health condition of the person. For young stage people, the severity is very low unless they have other chronic diseases like asthma, Chronic Obstructive Pulmonary Disease (COPD), tuberculosis and more breath related problems. For the aged people, the severity of the disease will be seen high. Many cases reported with common symptoms of loss of taste and anosmia or loss of smell which lasted nearly for a week or more. Some of them faced high fever and tiredness. The detailed review of the patients experiences and relevant information's extracted from different patients were reported in this section. Here, the different number of patient's information's were collected form the age group between 20 to 68 in the region of south Tamil Nadu, India.

Case Report 1: The different case is about young male persons from the age of 20 to 45 with healthy condition. They faced the common symptoms of fever, loss of taste and smell. Once the test got positive for COVID-19, they were hospitalized and they have given medicine to reduce the fever alone. Once the temperature is reduced, they don't feel any other symptoms other than loss of taste and smell. After a week, they slowly regain their taste and smell. The test is taken again after reducing temperature which shown negative. The treatment given for them is only healthy diet and steam intake for three time per day. They have been quarantined for 14 days and asked for take rest at home.

Case Report 2: These cases are about young female persons of age 20 to 45 with healthy condition. Along with the common symptoms, they faced drowsiness, low back pain and abdominal pain which lasted for a week. They also faced continuous cough and breathing trouble for three to five days. They have given nebulizers for easy breath. CT scans were taken to know about the functioning of lungs. Some of them got their lung infected and have taken treatment for improving the lung function.

Case Report 3: These cases are young person of age 20 to 45 with some sort of chronic diseases. At starting, they have the common symptoms alone. But later, they faced severe breathing trouble along drowsiness and vomiting. Nebulizers were given to make them comfort in breathing and medication were given. Nearly two weeks, they were given nebulizers continuously. Even 
though medicines were properly given, the situation gets worsen. The respiratory system got severely affected. Nebulizers didn't support them for their breathing. They couldn't move of their own and lost their consciousness. They were moved to ventilators and nearly they went to comma stage. Treatments were taken continuously. After a week, they got consciousness and just able to move their fingers and shifted to Intensive care unit (ICU). Day by day, they got some improvements in their body and started to stand on their legs with the help of nurses. Physiotherapy has given for strengthening their hands and legs. Nearly after two months, they were able to do their own needs. Even after two months they are not fully recovered. They are facing difficulties like cough, tiredness and comfortless in walking.

Case Report 4: These cases are aged people from 45 to 65 with healthy condition. They have all the common symptoms along severe cough, breathing trouble, back pain and abdominal pain. Legs got swollen and body got too weak. They were facing difficult to take food. They feel nausea while intaking foods and medicine. Treatments were given according to their age and the ability to withstand with the medicines. Blood pressure and glucose level were continuously monitored. Most of their blood pressure got increased due to the fear about COVID-19. Proper guidance where given to them to get relax during the difficult situation. They were given healthy diets and asked to get complete rest for two weeks even though they got negative test result. Continuous monitoring is needed for them at least for a month because of getting stress may lead to other related diseases like brain related issues and cardiovascular problems.

Case Report 5: These cases are aged people from 45 to 65 with some chronic diseases. They feel very uncomforted during this situation. They have severe cough and breathing trouble along with body pain. Blood pressure got increased due to tension, glucose level is increased due to the diet and different medicine intake for breathing trouble. Sugar level and blood pressure varies drastically to its minimum and maximum level. Alternative medicines were given to reduce the pressure and sugar level. Nebulizers were given continuously for avoiding breathing trouble. It is very difficult to withstand with COVID-19 for them especially above the age of 60 .

Table 1: Summary of status of various characteristic features of COVID-19

\begin{tabular}{|c|c|c|c|c|c|c|}
\hline Case Report & Case 1 & Case 2 & Case 3 & Case 4 & Case 5 & Case 6 \\
\hline Age & 20 & 42 & 38 & 45 & 56 & 64 \\
\hline Gender & Female & Male & Female & Female & Male & Female \\
\hline $\begin{array}{l}\text { Previous Medical } \\
\text { History }\end{array}$ & Wheezing & Chronic Asthma & Healthy & Healthy & Heart bypass & Diabetics \\
\hline Cause of spread & Unknown & Unknown & From husband & Travel & Shopping & Gatherings \\
\hline Starting symptoms & Cough and fever & $\begin{array}{l}\text { Wheezing and } \\
\text { fever }\end{array}$ & Fever & $\begin{array}{l}\text { Loss of taste and } \\
\text { smell }\end{array}$ & Drowsiness & Fever \\
\hline Stages & Risk & Risk & Normal & Mild & Mild & Mild \\
\hline $\begin{array}{l}\text { Common } \\
\text { symptoms }\end{array}$ & $\begin{array}{l}\text { Loss of taste and } \\
\text { smell }\end{array}$ & $\begin{array}{l}\text { Loss of taste and } \\
\text { smell }\end{array}$ & $\begin{array}{l}\text { Loss of taste and } \\
\text { smell }\end{array}$ & $\begin{array}{l}\text { Loss of taste and } \\
\text { smell }\end{array}$ & $\begin{array}{l}\text { Loss of taste and } \\
\text { smell }\end{array}$ & $\begin{array}{l}\text { Loss of taste and } \\
\text { smell }\end{array}$ \\
\hline Admitted date & August 16 & June 24 & June 27 & September 22 & September 15 & September 2 \\
\hline Days in ICU & 16 & 11 & - & - & - & - \\
\hline Ventilator period & 7 & 3 & - & - & - & - \\
\hline Discharge date & September 20 & July 14 & August 4 & October 5 & September 25 & October 4 \\
\hline Test taken & $\begin{array}{l}\text { Blood sugar level, } \\
\text { Blood pressure, } \\
\text { CT and MRI scans, } \\
\text { X-ray for chest }\end{array}$ & $\begin{array}{l}\text { Blood sugar level, } \\
\text { Blood pressure, } \\
\text { X-ray and CT scan }\end{array}$ & Temperature & CT scan & $\begin{array}{l}\text { Blood sugar level, } \\
\text { Blood pressure, } \\
\text { X-ray }\end{array}$ & $\begin{array}{l}\text { Blood sugar level, } \\
\text { Blood pressure, } \\
\text { X-ray and CT scan }\end{array}$ \\
\hline Effects & $\begin{array}{l}\text { Wheezing, } \\
\text { Pneumonia, lungs } \\
\text { got affected, } \\
\text { Comma stage for } \\
6 \text { days }\end{array}$ & Wheezing & Fever & $\begin{array}{l}\text { Wheezing, lungs } \\
\text { got affected, } \\
\text { abdominal pain }\end{array}$ & $\begin{array}{l}\text { Cough, variation } \\
\text { in blood sugar and } \\
\text { pressure level, } \\
\text { fever }\end{array}$ & $\begin{array}{l}\text { Cough, variation } \\
\text { in blood sugar \& } \\
\text { pressure level, } \\
\text { body pain and } \\
\text { breathing trouble }\end{array}$ \\
\hline
\end{tabular}




\begin{tabular}{|l|l|l|l|l|l|l|}
\hline Case Report & Case 1 & Case 2 & Case 3 & Case 4 & Case 5 & Case 6 \\
\hline Treatment & $\begin{array}{l}\text { Medication for } \\
\text { fever, cough, } \\
\text { nebulizers, } \\
\text { improvement for } \\
\text { lung functioning } \\
\text { and physiotherapy }\end{array}$ & $\begin{array}{l}\text { Medication for } \\
\text { fever, cough, } \\
\text { nebulizers, } \\
\text { improvement for } \\
\text { lung functioning }\end{array}$ & $\begin{array}{l}\text { Medicine to } \\
\text { reduce fever, } \\
\text { steam intake for 3 } \\
\text { times per day and } \\
\text { healthy diet }\end{array}$ & $\begin{array}{l}\text { Nebulizers and } \\
\text { healthy diet }\end{array}$ & $\begin{array}{l}\text { Insulin, Nebulizers } \\
\text { and healthy diet }\end{array}$ & $\begin{array}{l}\text { Insulin, Nebulizers } \\
\text { and healthy diet }\end{array}$ \\
\hline After COVID-19 & $\begin{array}{l}\text { Strength less in } \\
\text { body }\end{array}$ & Continuous cough & Normal & Abdominal pain & Light cough & Continuous cough \\
\hline
\end{tabular}

\section{Discussions}

The different study on the analysis of 2019-nCoV provides the necessary guidelines to the society. Although, this virus is spreading very fast in all over countries and affecting many people in very effective manner. In such pandemic situations, there is a huge demand for knowing a complete guideline to live with this virus. The different researchers from various bio and engineering domains of science have been started their research long back to develop the vaccine to treat this virus. Until then, we as a people need to be follow the instructions given by their government. Currently, the test for COVID-19 is performed through RT-PCR test by collecting nasopharyngeal swabs. Here, the test can be done by the cycle threshold (Ct) based on the symptom's onset per day. Meaning of the cycle threshold indicates replication cycles count for producing a fluorescent signal. As per the literature, the value below 40 is reported as positive PCR. This value may be reduced for severely infected patients. In this paper, we were compiled and reported the necessary information's on the starting phase of corona virus, life at hospital, effect of corona virus after treatment in table 1. The information's provided in this paper is collected from different patients infected by this coronavirus. This will help the entire society to know the nature of this virus and able to handle the situations very confidently if infected.

Possible criteria for COVID-19 infection: Fig.1 shows the possible criteria which leads more chance of getting infection from the affected patients. It is very important for the society to avoid these possible key features. This will help to control the spread of this virus among the population. The report shown in table 1 indicated that the unwanted shopping, gatherings more than one hundred peoples and non-necessary travel leads more choice for getting the infections and also giving way to spread this virus to human society.

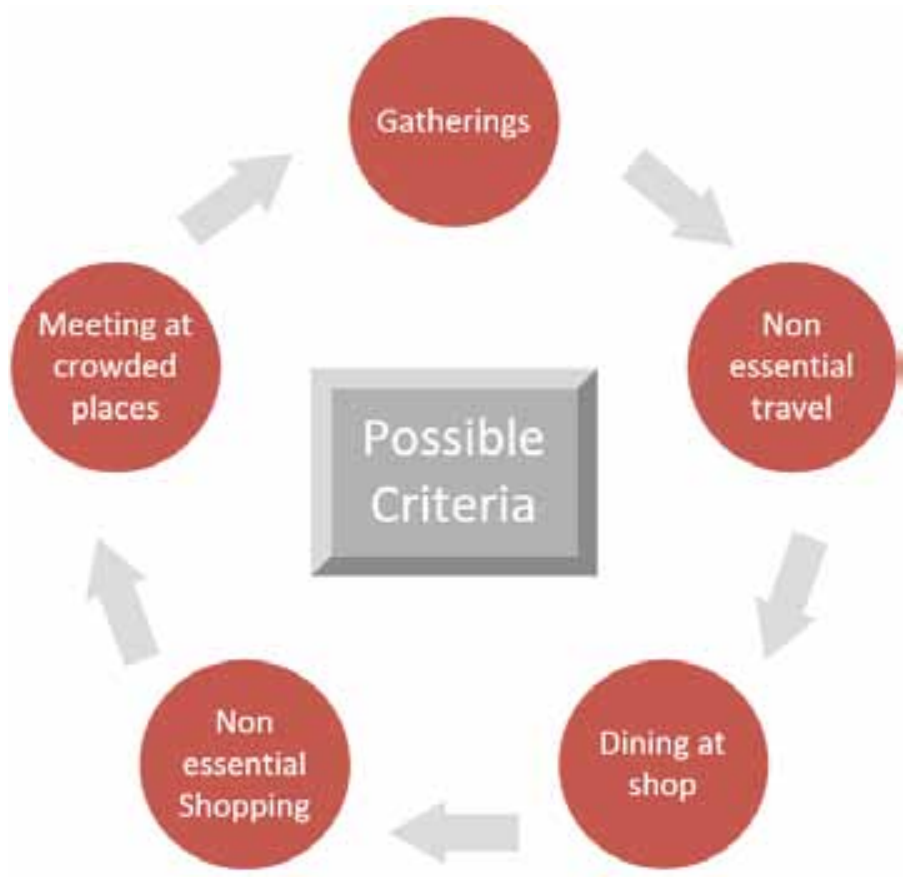

Fig. 1 Criteria to avoid COVID-19 infection during Pandemic situations 
Safety measures considered for COVID-19 infection: From the data observed from the infected patients, it is noticed that the given safety measures will provide an efficient control scheme to live with this coronavirus. The important safety measures listed in Fig.2 enable us to move forward with day by day activities with coronavirus.

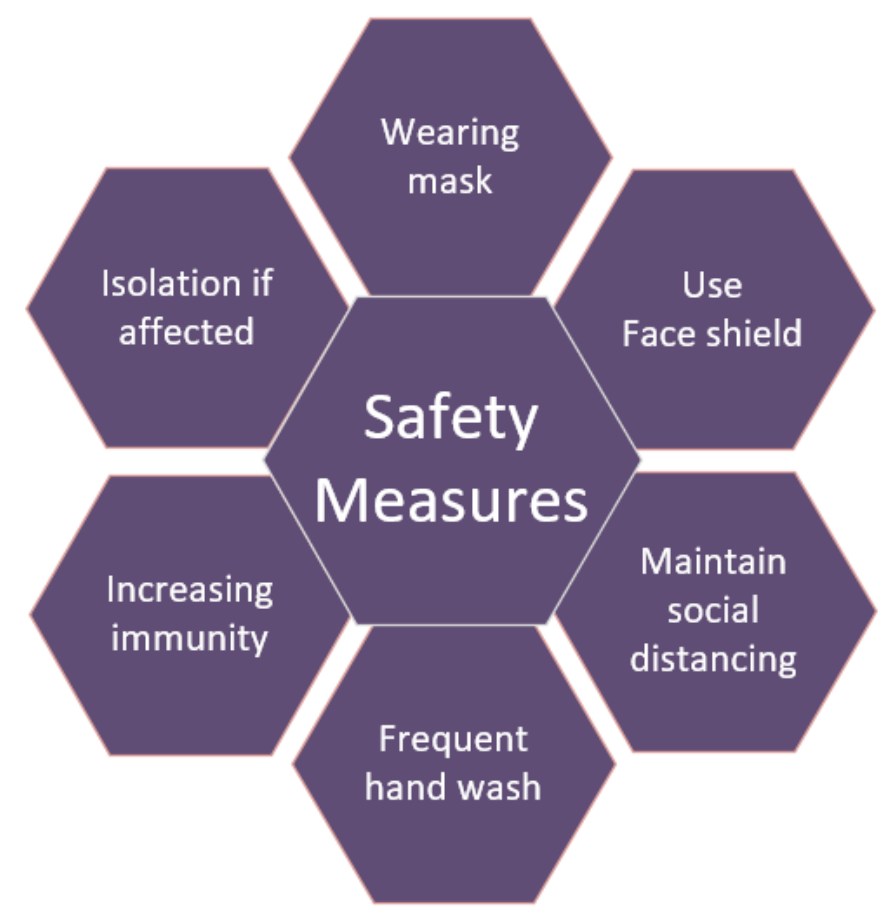

Fig. 2 Safety measures to live with COVID-19

Stages of COVID-19 in patient health: The effect of COVID-19 in infected patient varies with respect to individual body conditions. The case reports from section 2 clearly indicated the effects of COVID-19 for different age groups and their health conditions. The entire life period of the infection is categorized into four main stages as shown in Fig.3.

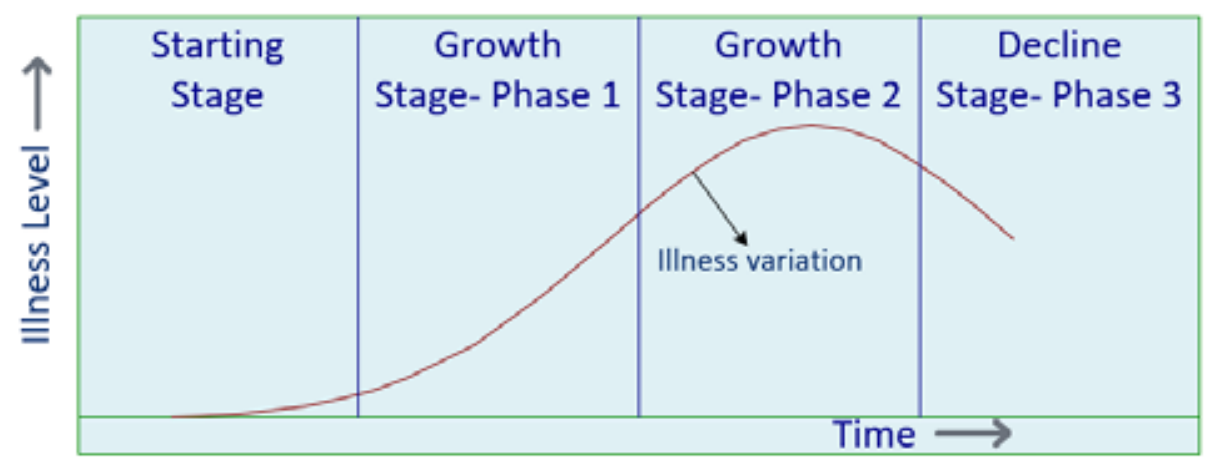

Fig. 3 Health illness level variation with time

Based on the case reports presented in this paper, the medical providers have given the best treatment to fight with this virus. According to the research on the coronavirus and published literature papers, the medicines recommended for treating this virus and controlling the effect of its impact on human health under growth stage phase 1, 2 are mainly Remdesivir, Chloroquine, Arbidol and Kaletra, lopinavir/ritonavir, nucleoside analogues, 
neuraminidase inhibitors and peptide EK $1^{7,8,9}$. Also, the infected patient admitted in the hospital were provided healthy foods to boost their body immunity. From this, it was observed to take healthy food help to control the effectiveness of this virus.

Recommended best practices: Based on the information's gathered from different infected patients, it is recommended that given health support measures will provide enough support to face these pandemic situations very effectively. Due to this pandemic, many people are affected by various health issues such as cardiovascular problems, increasing blood pressure, high range of blood glucose level, improper handling of food habits, mental stress, unwanted thinking which leads to critical illness. The research has been started for developing the vaccine for this virus by investigating the dynamic features of this virus. This novel coronavirus can create a problem as multi organ infections in various animals and humans specific to respiratory tract infections. Finally, it leads to respiratory failure towards death. Therefore, it is necessary to prevent the spread of this virus among the human population and also follow safety measures to safe ourselves. As per the information given by scientific and medical community, no vaccine has been successfully developed for fighting this virus. This will develop a fear inside human mind and reduced their ability to perform their duties. In order to help the society, we are reviewed the different infected patients and listed some of the recommended activities which are listed in Fig.4. These steps help to improve your health in physically and mentally. These approaches will strengthen your mind and allow you to perform your thinking in positive manner which leads to successful life in this pandemic situation.

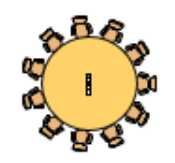

Round robin scheduling

Plan to schedule your days with activities and maintain round robin scheduling approach to deal very day.

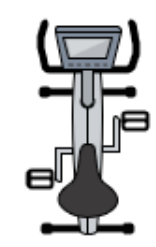

\section{Maintain body health}

Perform routine exercises at home at least 30 minutes per day and drinking more water, taking healthy foods.

\section{Balancing health conditions}

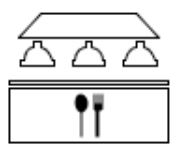

Avoid late taking food and maintain health diet to support your body health at balance conditions

\section{Spending time}

1 To continue to work with others, spending time to talk with everyone based on your work

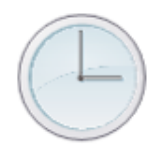

\section{Living with happy}

To live with happy environments.

3 Share your thoughts to family members and feel more comfortable

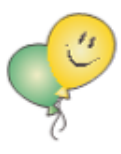

\section{Avoid mental stress}

Perform yoga daily to avoid mental stress and play games or doing your interested activities

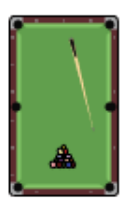

Creating awareness

Know the importance of wearing

mask, face shield, hand gloves, hand wash and have practice to use it

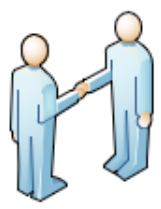

Fig. 4 Recommended best practices to live with COVID-19 


\section{Conclusion}

This paper highlighted the case reports from infected patients and provide the necessary guidelines to the society to live with this COVID-19. The effects induced by this virus becomes very critical in human life. The different stages of COVID-19 by infected patients were compiled and reported as useful information's to follow by the people to fight COVID-19. This will help the society to know more details about infection effects, treatment procedures and life at hospital. Based on these case report, it is concluded that effect of this virus can be controlled very easily through the pre-medicine at hospital centers and following the effective health safety measures mentioned in this paper will help to control the spread of 2019-nCoV.

Acknowledgement: The authors thanks all the participants to provide their experiences and suggestions to the society for fighting COVID-19.

Ethical Approval: Not applicable

Patient Inform Consent: While preparing a case report and for publication patient's informed consent has been taken.

Conflict of Interest: The Author declares that there are no conflicts of interest.

Funding: Not applicable

\section{References}

1. C. Ceraolo, F. Giorgi, Genomic variance of the 2019-ncov coronavirus., J Med Virol. 2020; 92 (5): $522-528$.
Medico-legal Update, April-June 2021, Vol. 21, No. 2

939

2] J. Cui, F. Li, Z. Shi, Origin and evolution of pathogenic coronaviruses., Nat Rev Microbiol. 2019; 17 (3): 181-192.

3. Erika Sifuentes-Rodriguez, Deborah PalaciosReyes, Covid-19: The outbreak caused by a new coronavirus, Bol Med Hosp Infant Mex. 2020; 77 (2): 47-53.

4] C. Huang, Y. Wang, X. Li, L. Ren, J. Zhao, Y. Hu, Clinical features of patients infected with 2019 novel coronavirus in wuhan, china, Lancet. 2020; 395: 497-506.

5] R. Lu, X. Zhao, et.al, Genomic characterization and epidemiology of 2019 novel coronavirus: implications for virus origins and receptor binding., Lancet. 2020; 395 (10224) 565-574.

6] C.-C. Lai, T.-P. Shih, W.-C. Ko, H.-J. Tang, P.R. Hsueh, Severe acute respiratory syndrome coronavirus 2 (sars-cov-2) and coronavirus disease-2019 (COVID-19): The epidemic and the challenges, International Journal of Antimicrobial Agents. 2020; 55 (3): 105924.

7. Michelle L. Holshue, M.P.H., Chas DeBolt, M.P.H et al. First case of 2019 novel coronavirus in the United States. N Eng J Med. 2020; 382 (10): 929936.

8. Manli Wang, Ruiyuan Cao, Leike Zhang, et al. Remdesivir and chloroquine effectively inhibit the recently emerged novel coronavirus (2019-nCoV) in vitro. Cell Res 2020; 30(3): 269-271.

9. Jianjun Gao, Zhenxue Tian, Xu Yang. Breakthrough: Chloroquine phosphate has shown apparent efficacy in treatment of COVID-19 associated pneumonia in clinical studies. Biosci Trends. 2020: 14 (1): 72-73. 